\title{
ISLAM WAHIDIYAH \\ (Ajaran dan Pengamalan Shalawât Wahidiyah dalam Mainstream Islam Masyarakat Madura)
}

\author{
Moh. Zahid
}

(Program Pascasarjana UIN Sunan Kalijaga Yogyakarta, jln. Marsda Adi Sucipto

Yogyakarta,email: Zahid_mohd@yahoo.com)

\begin{abstract}
Abstrak
Artikel ini merupakan hasil penelitian tentang pokok-pokok Ajaran Wahidiyah yang berintikan upaya untuk taqarrub ila Allâh (pendekatan diri kepada Allah) melalui pengamalan Shalawât Wahidiyah karya KH. Abdoel Madjid Ma'ruf, pengasuh Pondok Pesantren Kedunglo Kediri. Ciri khas ritual pengamalan Shalawât Wahidiyah adalah tangis dalam mujâhadah (kesungguhan), nidâ' (panggilan-menyeru) dengan berdiri menghadap empat arah, tasyaffu' (permohonan syafaat), dan istighrâq (pemusatan pikiran dan perasaan kepada Allah). Pada aspek Ajaran Islam Wahidiyah tidak ditemukan aqîdah yang secara menyakinkan bertentangan dengan syarîah meskipun sebagian kiai mempersoalkan keabsahannya. Sedangkan pada aspek pemahaman dan pengamalannya ditemukan ada penyimpangan dari pokok Ajaran Wahidiyah dan oleh sebagian kiai dan pemuka masyarakat dianggap telah membahayakan dan bertentangan dengan syarî'ah baik aqidah, amaliyah dan khuluqiyah serta dipandang meresahkan masyarakat dari sisi ritual pengamalan ajaran maupun terhadap keharmonisan praksis keberagamaan.
\end{abstract}

\begin{abstract}
This article is a research report about the essential teaching of Wahidiyah that the point is an attempt of taqarrub ila Allâh (to approach God and ask for His help) throughout the implementation of Shalawât Wahidiyah (prayer to honor the Prophet p.b.u.h.). The Shalawât Wahidiyah is composed by KH. Abdoel Madjid Ma'ruf, the owner of Islamic boarding school of Kedunglo Kediri. The characteristic of implementation of Shalawât Wahidiyah ritual is Crying about mujâhadah (truthfulness), nidâ' (appealing), tasyaffu' (request of syafa'at/intercession), and istighrâq (concentration and focus Allah). There is no controversial aspect of aqîdah in Wahidiyah
\end{abstract}


teaching, even though some Muslim scholars are still questioning its legality. From the aspects of understanding and implementation, it can be identified that Wahidiyah teaching deviates against syarî'ah (Islamic law), aqidah (tenet), amaliyah (implenetation), and khuluqiyah.

\section{Kata-kata Kunci}

shalawât Wahidiyah, ajaran Islam, syarî'ah, dan sesat.

\section{Pendahuluan}

Islam Wahidiyah secara resmi dibentuk pada Tahun 1963 di Kedunglo Kediri. Berawal pada bulan Juli 1959, Hadlarah al-Mukarram Romo Kyai Haji Abdoel Madjid dari desa Bandar Lor Kodya Kediri, menerima suatu isyârah gaib dalam keadaan terjaga dan sadar (bukan mimpi) agar dirinya "mengangkat nasib masyarakat." 1 Dalam isyârah ghaib yang diterimanya, dia diperintah agar memperbaiki dan membangun mental masyarakat khususnya dengan jalan bathiniyah berupa kesadaran kepada Allah swt dan Rasul-Nya saw. Dia senantiasa ber-mujâhadah kepada Allah swt dengan memperbanyak baca shalawât seperti shalawât Badawiyah, shalawât Nâriyah, shalawât Munjiyat, dan shalawât Masisiyah. Kemudian muncul isyârah ghaib yang kedua sebagai peringatan terhadap isyârah ghaib yang pertama agar dia segera berusaha memperbaiki mental masyarakat melalui saluran bathiniyah. Tidak lama setelah kejadian itu, dia menerima lagi isyârah ghaib yang ketiga ${ }^{2}$ berupa rangkaian bacaan sebagai berikut:

$$
\text { 7x الى حضرة سيدنا محمد صلى الله عليه وسلم الفاتحة }
$$

\footnotetext{
* Artikel ini disarikan dari naskah hasil penelitian kolektif yang dilakukan oleh tim peneliti, Moh. Zahid (Ketua tim), Abd. Rafik dan Saiful Hadi (masing-masing sebagai Anggota tim).

1 Sholyhan Masykoeri, Jalan Kebenaran (Surabaya: Yayasan Baitul Mukmin, 1967), hlm. 80 .

2 Ibid.
} 
والى حضرة غوث هذا الزمان وأعوانه وسائر اولياء الله رضي الله تعالى عنهم

7x الفاتحة

اللهم ياواحد يااحد. ياواجد ياجواد. صل وسلم وبارك على سيدنا محمد

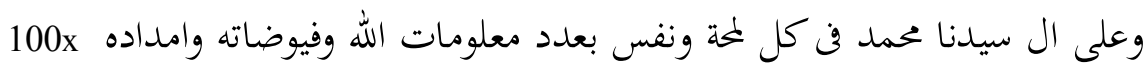
اللهم كما انت اهله. صل وسلم وبارك على سيدنا ومولانا وشفيعنا وحبيبنا وقرة اعيننا محمد صلى الله عليه وسلم كما هو اهله. نسألك اللهم بحقه ان تغرقنا في لجة بحر الوحدة. حتى لانرى ولانسمع ولانجد ولانحس ولانتحرك ولانسكن الا بها.

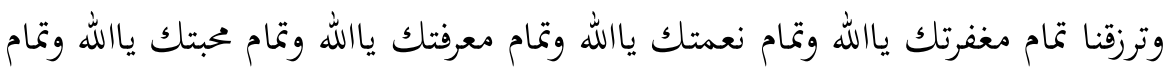
رضوانك ياالله وصل وسلم وبارك عليه وعلى اله وصحبه. عدد ما احاط به علمك

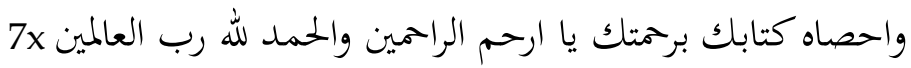
ياشافع الخلق الصلاةوالسلام ؟ عليك نورالخلق هادالانام واصله وروحه ادركنى فقد ظلمت ابدا وربنى وليس لي يا سيدى سواك ؟ فان تردكنت شخصاهالكا يا سيدي... يا رسول الله يا ايها الغوث سلام الله ع عليك ربني باذن الله وانظر الى سيدي بنظرة ؟ موصلة للحضرة العلية يا شافع الخلق حبيب الله ؟ صمراته عليك مع سلامة ضلت وضلت حيلتى فبلدتيٍخذ بيدي يا سيدي والامة يا سيدي... يا رسول الله يا ربنا اللهم صل سلم على محمد شفيع الامة والال واجعل الانام مسرعينٍ بالواحدية لرب العالمين 


$$
\begin{aligned}
& \text { يا ربنا اغفر يسر افتح واهدنا } \\
& \text { اللهم بارك فيما خلقت وهذه البلدة يا الله, وفى هذه البحاهدة يا الله 7x استغراق (ديم } \\
& \text { تيداك ممباج افا افا. سكنف فرهاتيان ظاهر باطن, فيكران دان فراساءن ديفوستكان } \\
& \text { هيا كفدا الله. تيدأ ادا اجارا سلاهين الله) الفاتحة ـ الدعاء: } \\
& \text { بسم الله الرحمن الرحيم. (اللهم بحق اسمك الاعظم وبجاه سيدنا محمد صلى الله عليه }
\end{aligned}
$$

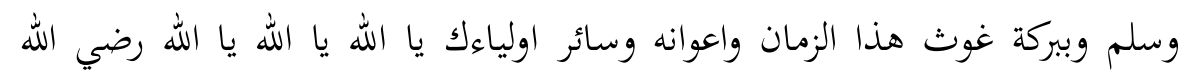

$$
\begin{aligned}
& \text { عنهم 3x) بلغ جميع العالمين نداءنا هذا واجعل فيه تأثيرا بليغا 3x) فانك على كل } \\
& \text { شيئ قدير وبلاجابة جدير 3x)ففروا الى الله 7x. وقل جاء الحق وزهق الباطل ان }
\end{aligned}
$$

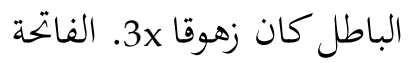

Di antara ciri khas pengamalan shalawât Wahidiyah adalah tangis dalam mujâhadah (kesungguhan), nidấ (panggilan-menyeru) dengan berdiri menghadap empat arah, tasyaffu' (permohonan syafaat), dan istighrâq (pemusatan pikiran dan perasaan kepada Allah). ${ }^{3}$ Sedangkan pokok ajaran yang senantiasa diperjuangkan oleh komunitas penganut ajaran Islam Wahidiyah meliputi: li Allah, bi Allah, li al-Rasûl, bi al-Rasûl, li al-ghawts, bi al-ghawts, yu'thî kulla haqq haqqah, taqdìm al-aham fa al-aham, tsumma anfa` fa al-anfa`.

Ajaran ini berkembang pesat di tanah air, bahkan tersebar ke luar negeri. ${ }^{5}$ Kehadiran Islam Wahidiyah di Madura disambut oleh sebagian masyarakat, termasuk di Kabupaten Pamekasan. Di beberapa lokasi di Pamekasan, pemahaman dan pengamalan ajaran Islam Wahidiyah ini dipersoalkan oleh kiai dan pemuka masyarakat. Di dusun Barat desa Lenteng kecamatan Proppo, misalnya, seorang pengamal shalawât Wahidiyah (Ach. Mudzhar Mauludi) dinyatakan telah sesat oleh JTMD dan JKTM yang dimotori oleh KH. Ali Karrar

\footnotetext{
${ }^{3}$ Departemen Penyiaran dan Pembinaan Wahidiyah Pusat, Bahan Up Grading Da'i Wahidiyah (Kediri: Yayasan Perjuangan Wahidiyah, 1999), hlm. 7.

4 Perjuangan Shalawât Wahidiyah Pusat (PSWP), Risalah Tanya Jawab Shalawât Wahidiyah dan Ajarannya (Kediri: Badan Usaha Wahidiyah Pusat, 1990), hlm. 6.

${ }^{5}$ Masykoeri, Jalan Kebenaran, hlm. 83.
} 
Shinhaji. Kondisi serupa juga terjadi di Desa Branta Pesisir Kecamatan Tlanakan Pamekasan. Di desa tersebut, warga masyarakat yang resah atas kehadiran dan ritual pengamalan Shalawât Wahidiyah.

Penolakan atas ajaran Islam Wahidiyah di dua desa itu disebabkan keberadaan ajaran, pemahaman, dan pengamalannya berbeda dengan mainstream pemahaman ajaran baku ajaran Islam yang sudah mapan di kalangan masyarakat. Terlebih lagi, perbedaan itu tidak hanya pada ranah figh namun sudah sampai pada ranah aqîdah. Di antara ajarannya adalah keberadaan ghawuts al-zamân, nidấ empat penjuru, dan bahr al-wahdah.

\section{Kajian Teori}

Kebudayaan dapat menjadi fondasi dan orientasi dalam bertindak dan berfikir yang didasari oleh pengalaman-pengalaman fundamental kehidupan. Sebab itulah kebudayaan tidak dapat dilepaskan dari kerangka kehidupan individu dan masyarakat. Sedangkan Agama, pada sisi lain, merupakan suatu sistem yang berinteraksi dengan budaya. Secara sistematik, agama mengatur hubungan manusia dengan Tuhan, manusia dengan manusia, dan manusia dengan lingkungannya dalam bentuk pranata-pranata agama. Agama tidak mengandung nilai-nilai di dalam dirinya tetapi memuat ajaran-ajaran yang menanamkan nilai-nilai sosial kepada penganutnya sehingga menjadi salah satu elemen pembentuk sistem nilai budaya. ${ }^{6}$

Dalam praksis kemasyarakatan, dikenal istilah kebudayaan transformatif, yaitu proses pendekatan manusia kepada Tuhan yang terus dikembangkan dan diperkaya sehingga mendekati kualifikasi ilahiah sehingga dapat mempertinggi martabat kemanusiaam. Inilah basis etis ajaran Islam yang menjadi dasar seluruh gerak kehidupan sosial, ekonomi, dan politik di tingkat lokal dalam konteks upaya pemberdayaan masyarakat Pamekasan.

Pandangan yang menganggap identitas budaya sebagai sesuatu yang sengaja dibangun jelas bertalian dengan seperangkat kepercayaan relatif seputar konsep budaya. Oleh karena itu, kebudayaan dipandang sebagai produk dari proses-proses budaya

${ }^{6}$ Zamakhsyari Dofier dan Abdurrahman Wahid, "Penafsiran kembali Ajaran Agama; Dua kasus dari Jombang", Prisma, No. 3 (Jakarta; LP3ES, 1978), hlm. 27. 
sebelumnya dan sebagai sesuatu yang terbuka bagi segala reinterpretasi dan akomodasi gagasan-gagasan baru karena "ausnya" komponen-komponen pemahaman lama. Dalam pertaliannya dengan konseptualisasi kebudayaan inilah identitas budaya tak hanya constructed, tetapi juga contexted. Sebagai bagian dari kebudayaan, tradisi berposisi sebagai elemen penyangga budaya. Dalam masalah tradisi ada dua hal yang sangat penting, yaitu pewarisan dan konstruksi. Pewarisan menunjuk kepada proses penyebaran tradisi dari masa ke masa, sedangkan konstruksi menunjuk kepada proses pembentukan atau penanaman tradisi kepada orang lain.

Menurut Cyrill Glasse dalam Ensiklopedia Islam, shalawât diartikan sebagai do'a untuk Nabî Muhammad (shalawât 'ala al-Nabî). Kata shalâh, akar kata shalawât, mengisyaratkan makna tentang peribadatan ritual (shalât), sedangkan kata kerjanya shallâ yang berarti menyanjung, memberkahi, dan bahkan sering diterjemahkan dengan mendoakan).7 Shalawât merupakan amalan dzikir yang diucapkan oleh setiap individu muslim, yakni tidak lepas dari upaya pemahaman dan pengamalan asketisme (zuhd) yang berkembang sejak zaman atau abad pertama Hijriah, bahwa amalan tersebut benarbenar berdasarkan ajaran Islam yang bersumber dari al-Qur`an, alSunnah, maupun praksis kehidupan Nabî.

Demikian pula shalawât Wahidiyah, yaitu adalah rangkaian do'a kepada Nabî saw. Rangkaian do'a tersebut tertulis di dalam naskah shalawât Wahidiyah yang dilengkapi dengan tatacara dan adab pengamalannya. Sedangkan secara operasional shalawât Wahidiyah adalah alhamdulillâh, bifadl-lillâh warahmatih. Dalam naskah itu disebutkan bahwa pengamalnya akan banyak dikaruniai berbagai manfaat, antara lain kejernihan hati, ketenangan batin, ketenteraman jiwa, peningkatan daya ingat, daya sadar, daya kenal (ma'rifah), dan kedekatan diri kepada Allah dan Rasulullah saw. Manfaat lainnya,

\footnotetext{
7 Cyril Glasse, Ensiklopedi Islam (Ringkas), terj. Ghufron A. Mas'adi, Edisi 1 (Jakarta: Raja Grafindo Utama, 1989). Shalawât 'alâ al-Nab̂̂ merupakan istilah yang berasal dari bahasa Arab, yang akar katanya mengandung pengertian "mengagungkan" Dalam hal ini al-Qur'an menyatakan "Sesungguhnya Allah dan para Malaikat-Nya menurunkan berkah dan keselamatan kepada Nabî Muhammad, wahai orang-orang yang beriman hendaknya engkau memohonkan berkah untuknya (33:56). Umat Muslim membacakan sejumlah shalawât dalam berbagai ritual dan upacara keagamaan. Bacaan do'a senantiasa diiringi dengan bacaan shalawât kepada Nabî Muhammad saw.
} 
berdimensi lahiriyah dan batiniyah serta duniawi dan ukhrawi. Dasar pengamalan shalawât kepada Nabî Muhammad saw adalah alQur`an Surat al-Ahzab (33): 56 sebagai berikut:

"Sesungguhnya Allah dan para malaikat-Nya membaca shalawât kepada Nabi; Wahai orang-orang yang beriman, bacalah shalawât dan sampaikan salam sebaik-baiknya kepadanya".

Tak terkecuali bagi para pengamal shalawât Wahidiyah, kaum Muslim pun benar-benar menyadari bahwa membaca shalawât kepada Baginda Nabî saw merupakan kewajiban agamawi dan keniscayaan nurani. Adanya kesadaran itu berpijak pada: (a) perintah Allah untuk membaca shalawât pada tiap shalat maktûbah, mandûbah, nâfilah dan baca doa, (b) jasa-jasa Baginda Nabî saw bagi pencerahan kehidupan manusia dan rahmat bagi alam semesta, dan (c) syafa'ah Rasulullah saw diberikan bagi kaum muslimin yang gemar membaca shalawât sebagai pertanda kecintaan dan dukungan mereka atas pribadi beliau.

\section{Metode Penelitian}

Dalam penelitian ini digunakan pendekatan kualitatif yang menghasilkan data berupa deskripsi, penuturan lisan, narasi tulisan, dan paparan perilaku yang dapat diamati dari subjek kajian. ${ }^{8}$ Pendekatan itu digunakan sebagai upaya untu merumuskan dan pemahaman atas pengamalan Islam Wahidiyah dari perspektif mereka.

Lokasi penelitian ditetapkan di dua kecamatan, yakni Proppo dan Tlanakan dalam wilayah kabupaten Pamekasan. Pilihan tentang dua lokasi itu terutama didasarkan pada keunikannya, yaitu adanya kasus yang berkaitan dengan ajaran dan pengamalan Islam Wahidiyah yang dipandang sebagai "ajaran baru" oleh entitas warga masyarakat yang sudah baku dan mapan pemahaman ajaran Islamnya.

Pengumpulan data dilakukan untuk memperoleh data yang absah melalui penerapan 3 jenis metode, yaitu observasi, wawancara, dan dokumentasi. Metode observasi digunakan untuk merekam berbagai aktivitas tentang pengamalan penganut shalawât Wahidiyah

8 Arief Furchan, Pengantar Metode Penelitian Kualitatif (Surabaya: Usaha Nasional, 1992), hlm. 21. 
sebagai obyek penelitian dengan jalan mengamati suatu peristiwa atau gejala, baik secara langsung dilakukan oleh peneliti sendiri maupun secara tidak langsung yaitu dengan bantuan orang lain dan kemudian dipilah sesuai topik. Metode wawancara ${ }^{9}$ digunakan melalui dialog terfokus dan open ended untuk memperoleh konfirmasi, penjelasan, dan keterangan tentang aktivitas subjek dalam pengamalan shalawât Wahidiyah. ${ }^{10}$ Metode dokumentasi digunakan untuk memperoleh data tertulis dari sumber-sumber cetakan tentang pengamalan shalawât Wahidiyah. Melalui penerapan metode tersebut dapat diperoleh data akurat dari sumber asli cetakan, yaitu dokumen tentang ajaran dan arsip Yasasan Penyiaran Shalawât Wahidiyah. ${ }^{11}$

Teknik analisis yang digunakan adalah analisis taksonomik yaitu himpunan kategori-kategori yang diorganisasi berdasarkan suatu semantic relationship. 12 Tabel taksonomi terdiri dari tiga point, yaitu fokus, klasifikasi fokus, dan komponen fokus. Tujuan pembuatan tabel taksonomi agar peneliti dapat menajamkan fokus kajian dan menetapkan kriteria inklusi dan eksklusi agar tersaring informasi faktual dan kontekstual pada seting penelitian.

\section{Hasil Penelitian dan Pembahasan}

1. Pokok-Pokok Ajaran Wahidiyah.

Inti ajaran Wahidiyah adalah upaya untuk taqarrub ilâ Allâh (mendekatkan diri kepada Allah) dengan cara mengamalkan Shalawât Wahidiyah yang dirumuskan oleh KH. Abdoel Madjid Ma'ruf pengasuh Pondok Pesantren Kedunglo Kediri. Sejak awal tidak ditemukan dalam ajaran shalawât Wahidiyah yang nyata-nyata dapat disimpulkan bertentangan dengan syarî'ah. Akan tetapi dimungkinkan ada kesalahpahaman sebagai akibat dari beberapa istilah dan "ajaran baru" seperti ghawts al-zamân, bahr al-wahdah, dan nidâ' empat penjuru.

2. Ciri Khas Ajaran Wahidiyah.

\footnotetext{
${ }^{9}$ Lexy Moleong, Metodologi Penelitian Kualitatif (Yogyakarta: Rake Sarasin, 1999), hlm. 135

10 K. Yin Robert, Yion D, Studi Kasus: Desain dan Metode (Jakarta: RajaGrafindo Persada, 1996), hlm. 108.

${ }^{11}$ Suharsimi Arikunto, Dasar-DasarResearch (Jakarta: Bina Aksara, 1991), hlm. 202

12Imron Arifin, Penelitian Kualitatif dalam Ilmu-Ilmu Sosial dan Kegamaan (Malang: Kalimasahada, 1996), hlm. 87.
} 
Pengamalan shalawât Wahidiyah memiliki ciri khas, yaitu tangis dalam mujâhadah, nidâ' dengan berdiri menghadap empat arah, tasyaffu', dan istighrâq. Hal ini terjadi karena di dalam tata cara mujahadah ada situasi yang menyebabkan mereka menangis, yaitu hudlûr, istihdlâr, tadzallul, tadhâlum, iftiqâr, syawq, dan mahabbah. Nidâ' menghadap empat arah maksudnya adalah berdiri menghadap empat penjuru dengan mengucapkan fafirrû ilallâh. Namun gambaran tentang pemahaman dan pengamalan shalawât Wahidiyah dijumpai pemahaman dan pengamalan yang menyimpang dari pokok-pokok ajaran Wahidiyah.

3. Pandangan Ulama.

Berbagai perbedaan (penyimpangan?) baik pada aspek pemahaman maupun aspek pengamalan antara pokok ajaran Wahidiyah dan mainstream keislaman publik oleh sebagian ulama (kiai) dan pemuka masyarakat dianggap telah membahayakan dan bertentangan dengan syarî'ah (aqîdah, amaliyah, dan khulîqiyah) di samping juga dianggap meresahkan masyarakat karena berbeda dalam pelaksanaan ritual ajaran.

Terdapat dua kasus pengamalan Shalawât Wahidiyah baik di daerah Proppo maupun di daerah Tlanakan kabupaten Pamekasan yang mendapatkan tanggapan pro dan kontra dari sebagian kiai dan pemuka masyarakat. Di Proppo, tanggapan-tanggapan terhadap pengamalan shalawât Wahidiyah dideskripsikan dari kutipan catatan lapangan berikut ini:

Menyikapi berbagai pernyataan dan praktik yang dilakukan oleh Ach. Mudzhar, KH. Ali Karrar Shinhaji sebagai ketua JTMD dan JKTM menyatakan bahwa: (1) pernyataan-pernyataan Mudzhar dapat disimpulkan telah sesat dan tertipu nafsu lawwâmah dengan tidak mendapatkan kemantapan dalam mengamalkan syari'at dzahir "dalam shalat, tilâwah, dan adzkar nabawiyah" dan hanya merasa menemui kemantapan dan keyakinan dekat dengan Allah melalui amalan Wahidiyah yang hanya bersandar kepada mu'allif KH. Abdoel Madjid Kediri, (2) Mudzhar telah sesat dengan meremehkan pengamalan syari'at, (3) Mudzhar telah terseret oleh syetan ke ujub (berbangga diri) dengan pengamalan shalawât Wahidiyah-nya itu. 
Mudzhar yang dikonfirmasi atas penilaian Kiai Karrar mengenai penilaian sesat itu memberi penjelasan dan klarifikasi, yaitu:

Saya tidak mengatakan suatu aliran tetapi amalan ajaran shalawât Wahidiyah. Saya tidak mengatakan sesuatu melebihi dari yang saya peroleh dari pengamalan-pengamalan lain. Perlu dijelaskan bahwa amalan shalawât Wahidiyah tidak mengenyampingkan amalan-amalan baik lainnya.

Dalam surat yang sama, Mudzhar juga menyampaikan penjelasan sebagai berikut:

(1) Penjelasan JTMD dan JKTM adalah benar apabila saya mengatakan dan meyakini demikian, tetapi adalah tidak benar kalau dikatakan saya sesat dan tertipu nafsu lawwamah, karena dengan bimbingan amalan shalawât Wahidiyah justru menambah kemantapan di dalam mengamalkan syari'at, (2) saya diperintah memperaktekkan shalawât tersebut dari awal hingga akhir, kemudian saya praktekkan bagaimana dikatakan meremehkan syari'at, karena praktek tersebut tidak ada hubungannya dengan meremehkan syari'at; sedangkan syari'at sebagaimana yang ada tetap saya amalkan/jalankan sesuai dengan kemampuan saya, bahkan saya melihat kebanyakan pengamal shalawât Wahidiyah yang dulu syariatnya morat-marit, dalam menjalankan bimbingan amalan shalawât Wahidiyah kenyataannya dalam menjalankan syariat semakin tertib/baik, (3) adalah tidak benar karena bimbingan amalan shalawât Wahidiyah dengan mengetrapkan niat lillâh, billâh, lirrasûl, birrasûl, berfaedah menjauhkan hati dari sifat 'ujub, riyâ' dan takabbur.

Demikian juga ada beberapa hasil temuan tentang pendapat Mudzhar yang membuat JTMD dan JKTM menekankan empat hal kepada Mudzhar, yaitu:

(1) Mudzhar harus kembali ke jalan syari at, dan menekankan dirinya memantapkan kembali dengan syari at, (2) Mudzhar harus melepas diri dari aliran dimaksud, dan menjauh diri dari pengikut-pengikutnya, (3) Mudzhar tidak diperkenankan membuka cabang aliran dimaksud, mendukungnya, dan atau mengadakan mujahadahnya di wilayah Kecamatan Proppo, dan 
(4) Mudzhar di dalam kesusahan dan kebingungannya hendaknya segera kembali ke jalan Allah melalui pengamalan taqwa dan bertawakkal kepada Allah, sebagaimana tertera di dalam al-Qur`an surat al-Thalâq (86): 2-3

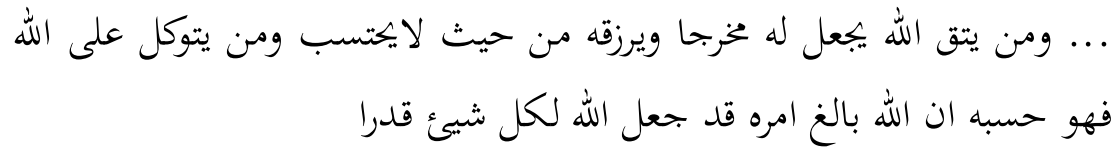

"Barangsiapa yang bertakwa kepada Allah niscaya Dia akan mengadakan baginya jalan keluar. Dan memberinya rizqi dari arah yang tiada disangka-sangkanya. Dan barangsiapa yang bertawakkal kepada Allah niscaya Allah akan mencukupkan (keperluan)nya. Sesungguhnya Allah melaksa-nakan urusan (yang dikehendaki)Nya. Sesungguhnya Allah telah mengadakan ketentuan bagi tiap sesuatu."

Sikap Mudzhar terhadap tekanan JTMD dan JKTM adalah sebagai berikut:

(1) Saya tidak pernah meninggalkan syari'at, bagaimana saya disuruh kembali, (2) saya tetap akan mengamalkan shalawât Wahidiyah karena mengamalkan shalawât dianjurkan oleh Allah swt dan Rasulullah saw, dan (3) saya bukan orang sebagaimana JTMD dan JKTM katakan, bukankah mengamalkan shalawât adalah bagian dari jalan kembali kepada Allah swt.

Kasus tentang pengamalan shalawât Wahidiyah di Tlanakan Pamekasan disampaikan oleh KH. Rahbini A bdul Latief, Katib Syuriyah PC NU Pamekasan. Dia berkomentar:

"Berdasarkan laporan yang disampaikan oleh Pengurus Ranting NU Branta Pesisir, pengamalan shalawât Wahidiyah di daerah itu banyak yang menyimpang dari ajaran syari'at Islam." Dia kemudian memberi contoh: "Pernyataan shalat bukan merupakan kewajiban adalah pernyataan yang sesat dan menyesatkan. Ijmâ' ulamâ telah menetapkan bahwa shalat wajib bagi umat Islam".

Kasus pengamalan shalawât Wahidiyah di Branta Pesisir lebih kepada minimnya pemahaman pengikutnya terhadap ajaran 
Wahidiyah. Hal ini disampaikan K. Moh. Zainuddin, BA, Pramu Penyiaran dan Pembinaan Yayasan Perjuangan Wahidiyah dan Pondok Pesantren Kedunglo Pamekasan.

"Apabila hal itu benar adanya maka hal tersebut adalah deviasi dari ajaran Wahidiyah yang memerlukan pembinaan lebih lanjut".

Meski demikian, Djufri Prawira Adi Praja (Ketua Departeman Penyiaran dan Pembinaan Wahidiyah Kabupaten Pamekasan) menyampaikan pembelaan atas putusan PC NU Pamekasan yang dituangkan dalam surat resmi No. 10/PW/KAB/PMK/IX/2006 tanggal 27 September 2006 yang isinya:

(1) Warga NU yang mengamalkan Shalawât Wahidiyah harus keluar dari NU. Yang menjadi pertanyaan kami, semenjak kapan NU mempunyai keputusan seperti itu? Sedang yang kami tahu muallif shalawât Wahidiyah juga termasuk bagian dari ulama NU yang juga pernah menjadi pengurus NU, bahkan al-mukarram almarhum KH. Abd. Wahab Hasbullah (Rais Am PBNU) sekitar tahun 1964 dalam resepsi ulang tahun Wahidiyah pertama tahun 1964 menyatakan iqrar kepada muallif shalawât Wahidiyah dengan pernyataan qabiltu ijazataka, (2) Adanya beberapa kalimat yang intinya: (a) menghina/melecehkan Pengasuh Perjuangan Wahidiyah dan Ponpes Kedunglo Kediri yaitu almukarram Romo (istilah Jawa) KH. Abdul Latif Madjid ra. (radiyallahuan), (b) menganggap pengamalan shalawât Wahidiyah meresahkan masyarakat, menyimpang dari kaidah syar'îyah bahkan keluar dari Islam, dan (c) memunculkan beberapa pernyataan yang diatasnamakan pengamal shalawât Wahidiyah yang semua itu hanya didasari laporan secara sepihak yang jelas-jelas datang dari orang-orang yang kontra terhadap Wahidiyah yang kebetulan menjadi salah satu Pengurus Ranting NU Branta Pesisir.

Dari dua kasus pengamalan shalawât Wahidiyah baik di Proppo maupun Tlanakan di Pamekasan, berdasarkan hasil Kajian dan penelitian MUI Kabupaten Pamekasan disimpulkan bahwa:

(1) Tidak ditemukan ajaran yang nyata-nyata dapat disimpulkan bertentangan dengan syarî'ah. Akan tetapi dimungkinkan ada kesalahpahaman sebagai akibat dari beberapa istilah "baru" seperti ghawts al-zamân, bahr al-wahhdah, dan nidâ' empat penjuru, 
(2) Tingkat pemahaman pengamal shalawât Wahidiyah tentang ajaran Wahidiyah sangat beragam dan ditemukan pemahamanpemahaman yang jauh menyimpang dari pokok-pokok ajaran Wahidiyah yang membahayakan baik aqîdah, 'amaliyah dan khuluqiyah, dan (3) Pengamalan shalawât Wahidiyah dalam beberapa kasus meresahkan masyarakat baik sebagai ritual pengamalan maupun akibat penyimpangan dari pokok-pokok ajaran Wahidiyah.

Dari paparan terdahulu dapat dipahami bahwa sebagai dasar pengamalan, berdasarkan kerangka teoritik konstruksi sosial Peter L. Berger,13 pengamal shalawât Wahidiyah melakukan penyesuaian yang dilakukan oleh mereka melalui tiga tahapan, yaitu:

1. Eksternalisasi, yakni proses penyesuian diri dengan dunia sosiokultural sebagai produk manusia. Dalam momen ini, realitas sosial itu ditarik ke luar diri individu. Sedangkan realitas sosial itu sendiri berupa proses adaptasi dengan teks-teks suci, seperti alQur`an, al-Hadits, hukum, norma, nilai, dan sebagainya, yang hal itu berada di luar diri manusia, sehingga dalam proses konstruksi sosial melibatkan momen adaptasi diri atau diadaptasikan antara teks-teks tersebut dengan dunia sosio-kultural. Dalam kaitan ini, pengamal ajaran Wahidiyah melakukan adaptasi diri melalui empat momen, yaitu:

a. Penyesuaian dengan al-Qur`an dan al-Hadits.

Penyesuaian ajaran pengamal shalawât Wahidiyah dengan alQur'an dan al-Hadits misalnya pada konsep lillah didasarkan pada firman Allah swt, di antaranya, al-Qur`an surat al-Dzâriyât (51): 56; Wa mâ khalaqtul jinn wa al-insa illâ liya budûn (Aku tidak ciptakan jin dan manusia, melainkan hanya untuk beribadah kepada-Ku). Sedangkan Hadits Nabî adalah: Hadits dari Mu'âdz bin Jabal: Akhlish al-amal yujzika minhul qalîl (Ihklaslah dalam beramal walau sedikit, niscaya kamu akan mendapat pahala). Demikian juga ajaran- ajaran yang lain.

b. Penyesuaian dengan Tradisi Lama.

${ }^{13}$ Untuk memahami kerangka teoritik Berger ini, baca Peter L. Berger dan Thomas Luckman, Konstruksi Sosial atas Realitas (Jakarta: LP3ES, 1990). 
Bentuk adaptasi seperti ini terlihat pada praktek pengalaman shalawât Wahidiyah diantaranya menangis saat mujâhadah dianggap suatu yang lumrah dan biasa dilakukan oleh orangorang terdahulu pada saat kesusahan dan kebahagiaan. Demikian juga nidâ' menghadap empat penjuru, dijelaskan bahwa praktek ini merupakan bentuk peniruan dari perbuatan Nabî Ibrâhîm. Juga tasyaffu' membaca shalawât dengan berdiri dikatakan merupakan kebiasaan orang Arab zaman dahulu jika menghormat pemimpinnya.

c. Penyesuaian dengan Menggunakan Kharisma Tokoh.

Pada tahun-tahun awal berdirinya ajaran ini pernah diadakan acara ulang tahun dengan mengundang para tokoh yang banyak. Bahkan ada di antara mereka yang merupakan tokoh nasional, seperti KH. Abd. Wahab Hasbullah, KH. Machrus Ali, DR. Idham Khalid dan KH. Hamim Jazuli.

d. Penyesuaian dengan Menggunakan Kekuatan Yuridis Pemerintah.

Bentuk ini dilakukan sehingga lahir keputusan Bakor Pakem Kejaksaan Tinggi Jawa Timur nomor; B-1161/I.5.1.1/1978, tanggal 17 Juli 1978 dan surat Kasi Polkam an. Asisten I/Intel, an. Kepala Kejaksaan Tinggi Jawa Timur tertanggal 16 Desember 1978, nomor B-1981/K.5.3.1./12/1978, juga surat Kepala Puslitbang I an. Kepala Badan Penelitian dan Pengembangan Agama nomor: P.II/3/294/1271/1979, tanggal 5 Nopember 1979 yang menyatakan bahwa ajaran ini tidak dilarang dan tidak termasuk Islam Jama'ah.

2. Objektivasi, yakni proses institusionalisasi dan legitimasi. Dalam prose situ, agen bertugas menarik dunia subyektivitasnya menjadi dunia obyektif melalui interaksi sosial yang dibangun secara bersama-sama. Momen ini dilakukan dengan empat langkah yaitu: (a) penyampaian informasi tentang akhlaqul kharimah dari penyusun shalawât Wahidiyah. Qamari Mukhtar dalam buku Sejarah dari Awal Perjuangan Wahidiyah menulis bahwa penyusun shalawât Wahidiyah ini tawadlu', muqtadlâ al-hâl, tidak pernah mengecewakan orang lain dan ngastiti ngati-ngati, (b) pemberitaan 
tentang keampuhan do'a shalawât Wahidiyah. Keampuhan do'a ini selalu disampaikan pada saat pengajian yang dilakukan oleh kelompok ini. Selain itu adanya mujâhadah khusus dan khushûshil khushîsh merupakan faktor yang menyebabkan ajaran ini "selalu diperlukan" oleh para pengamalnya yang selanjutnya disampaikan kepada orang lain, (c) pembentukan lembaga penyiaran (institusionalisasi). Untuk efektifnya dakwah yang dilakukan, maka pengamal shalawât ini membentuk sebuah lembaga yang berfungsi, di antaranya, mengkoordinir gerakan perjuangan yang pada 1964 bernama Pusat penyiaran Wahidiyah. Beberapa waktu kemudian nama tersebut diganti menjadi Panitia Penyiaran Shalawat Wahidiyah Pusat, dan diganti lagi menjadi Penyiar Shalawat Wahidiyah. Saat ini, ia bernama Yayasan Penyiar Shalawât Wahidiyah, dan (d) pembiasaan membaca do'a shalawât Wahidiyah (habitualisasi). Pembiasaan membaca do'a shalawât Wahidiyah ini dilakukan dengan jalan, di antaranya, pembentukan jenis mujâhadah yang bermacam-macam, seperti; harian (yawmiyah), mingguan (usbu'iyyah), bulanan (syahriyyah), triwulanan (rub'ussanah), tengah tahunan (nisfussanah), kubro, khusus, non stop, momentil (waqtiyah dan muqaddimah); dua, dispensasi atau penyederhanaan bacaan bagi yang belum hafal do'a shalawât Wahidiyah secara keseluruhan.

3. Internalisasi, yakni momen identifikasi diri dalam dunia sosio kultural. Internalisasi adalah proses individu melakukan identifikasi diri di dalam dunia sosio-kulturalnya. Dalam momen itu, terjadi penarikan realitas sosial ke dalam diri atau realitas sosial menjadi kenyataan subyektif. Pengamal shalawât Wahidiyah pada hakikatnya membentuk kelompok tersendiri atas rasa se identitas yang di sana tidak ditemui sekat interaksi karena mereka mempunyai ciri khas yang sama, tujuan gerakan yang sama, dan jalan perjuangan yang sama pula. Pada akhirnya, kelompok ini terus melakukan ritual sesuai dengan tuntunan versi mereka sebagai bentuk retensi atas ajaran Wahidiyah yang dianut. Ritual itu dikenal dengan sebutan mujâhadah. Namun apa pun istilah yang digunakan, sudah pasti bahwa motif penyebab dari kegiatan itu adalah mencapai kejernihan hati dan kesadaran kepada Allah swt. dan Rasul-Nya saw. Mereka terus melakukan 
habitualisasi amalannya dan senantiasa mengajak orang lain beramal seperti mereka. Hal ini dilaksanakan karena motif tujuan dari perjuangan gerakan Wahidiyah ini adalah terciptanya masyarakat yang senantiasa bergantung kepada Allah atau dalam istilah mereka "fafirru ilallah."

Setelah diperhatikan dengan seksama, ternyata dalam komunitas ini terjadi sakralisasi terhadap do'a shalawât Wahidiyah dan penyusunannya. Dalam masalah ini jelas terlihat bahwa anggota gerakan ini telah menempatkan alam sebagai subjek yang dapat memberikan manfaat "lebih", atau melampaui kebiasaan. Jadi alam ditempatkan dalam fenomena yang bukan profan, bukan dunia mutatis mutandis atau ipso facto.

\section{Penutup}

Hasil penelitian ini disimpulkan bahwa: Pertama, Ajaran Wahidiyah berintikan upaya untuk taqarrub ilâ Allâh (mendekatkan diri kepada Allah) dengan cara mengamalkan shalawât Wahidiyah yang disusun oleh KH. Abdoel Madjid Ma'ruf pengasuh Pondok Pesantren Kedunglo Kediri. Sejak awal tidak ditemukan ajaran yang nyata-nyata dapat disimpulkan bertentangan dengan syarî'ah. Akan tetapi dimungkinkan ada kesalahpahaman sebagai akibat dari beberapa istilah dan ajaran "baru" seperti ghawts al-zamân, bahr alwahdah, dan nidâ' empat penjuru. Kedua, Ciri khas pengamalan Shalawât Wahidiyah: tangis dalam mujâhadah, nidấ dengan berdiri menghadap empat arah, tasyaffu', istighrâq (memusatkan pikiran dan perasaan kepada Allah). Hal ini terjadi karena di dalam tata cara mujâhadah ada situasi yang menyebabkan mereka menangis, yaitu hudlûr, istihdlâr, tadzallul, tadhâlum, dan iftiqâr serta syawq dan mahabbah. Nidâ' menghadap empat arah maksudnya adalah berdiri menghadap empat penjuru dengan mengucapkan fafirrû ilâ Allâh. Namun pada aspek pemahaman dan pengamalan shalawât Wahidiyah dijumpai beberapa pemahaman dan pengamalan yang menyimpang dari Pokok-pokok ajaran Wahidiyah.

Pandangan masyarakat terhadap Islam Wahidiyah dapat disimpulkan: Pertama, pada aspek ajaran Wahidiyah tidak ditemukan ajaran yang secara menyakinkan bertentangan dengan syarî'ah. Meski sebagai akibat perbedaan penafsiran terhadap ajaran Wahidiyah, sebagian kiai mempersoalkan keabsahannya. Kedua, pada aspek 
pemahaman dan pengamalan ditemukan adanya penyimpangan dari pokok ajaran Wahidiyah dan oleh sebagian kiai dan pemuka masyarakat dianggap telah membahayakan dan bertentangan dengan syarî́ah baik aqîdah, 'amaliyah dan khulûqiyah. Pemahaman dan pengamalan shalawât Wahidiyah oleh sebagian ulama dan tokoh masyarakat juga dianggap meresahkan masyarakat baik dari sisi pelaksanaan ritual pengamalan maupun terhadap keharmonisan dalam masyarakat.

Berdasarkan kesimpulan tersebut, penulis merekomendasikan kepada kiai dan pemuka masyarakat yang menolak kehadiran ajaran Wahidiyah maka disarankan pengamalan Shalawât Wahidiyah hendaknya menyesuaikan dengan tuntunan Islam dan pengamalannya pun tidak meresahkan dan mengganggu warga masyarakat sekitarnya. Sedangkan adanya penyimpangan baik pada aspek pemahaman dan pengamalan hendaknya disikapi secara arif dan bijaksana. Hal ini pun merupakan kewajiban kaum Muslim untuk meluruskannya terutama pengurus dan pembina Yayasan Perjuangan Wahidiyah sendiri.

\section{Daftar Pustaka:}

Arifin, Imron. Penelitian Kualitatif Dalam Ilmu-Ilmu Sosial dan Kegamaan. Malang: Kalimasahada, 1996.

Arikunto, Suharsimi. Dasar-Dasar Research. Jakarta: Bina Aksara, 1991. Berger, Peter L. dan Luckman, Thomas. Konstruksi Sosial atas Realitas. Jakarta: LP3ES, 1990.

Departemen Penyiaran dan Pembinaan Wahidiyah Pusat, Bahan Up Grading Da'i Wahidiyah (Kediri:, Yayasan Perjuangan Wahidiyah, 1999)

Dhofier, Zamakhsyari dan Wahid, Abdurrahman. "Penafsiran kembali Ajaran Agama; Dua kasus dari Jombang", Prisma, No. 3, (Jakarta: LP3ES, 1978)

Furchan, Arief. Pengantar Metode Penelitian Kualitatif. Surabaya: Usaha Nasional, 1992.

Glasse,Cyril. Ensiklopedi Islam (Ringkas), Terj. Ghufron A. Mas'adi, Edisi 1. Jakarta: Raja Grafindo Utama, 1989. 
Masykoeri, Sholyhan. Jalan Kebenaran. Surabaya: Yayasan Baitul Mukmin, 1967

Moleong, Lexy. Metodologi Penelitian Kualitatif. Yogyakarta: Rake Sarasin, 1999.

Perjuangan Shalawât Wahidiyah Pusat (PSWP), Risalah Tanya Jawab Shalawât Wahidiyah dan Ajarannya. Kediri: Badan Usaha Wahidiyah Pusat, 1990.

Robert, K. Yin dan Yion D, Studi Kasus: Desain dan Metode. Jakarta: RajaGrafindo Persada, 1996. 